\title{
Nutritional Adequacy in Mechanically Ventilated Patient: Are We Doing Enough?
}

\author{
MS Kalaiselvan ${ }^{1} \odot$, AS Arunkumar ${ }^{2}$, MK Renuka $^{3}$, RL Sivakumar $^{4}$
}

\begin{abstract}
Background: Critically ill patients are under stress, leading to a catabolic response and higher energy expenditure. The associated malnutrition leads to adverse outcomes.

Aims and objectives: This study aims to assess the nutritional adequacy ( $>80 \%$ of prescribed calories) in mechanically ventilated (MV) patients and its effects on patients' outcomes. It also aims to identify the causes of deviation from the nutrition prescription.

Materials and methods: This is a prospective observational study involving all adult critically ill patients requiring MV for $>48$ hours. Patients were prescribed enteral nutrition (EN) targeted to achieve $25 \mathrm{kcal} / \mathrm{kg}$ (IBW) of energy and $1.2 \mathrm{~g} / \mathrm{kg}$ of proteins daily. Standard polymeric formula feeds were initiated as continuous infusion as per the feeding protocol in the intensive care unit (ICU). Data were collected on demography, body mass index (BMI), indication for ICU admission, admission category, and admission APACHE II and SOFA scores, and nutritional risk was captured with mNUTRIC score. Nutritional data on type of feed initiated, amount of calories prescribed/achieved, time taken to initiate feeds, reasons for not starting/delay in the initiation of feeds, time taken to achieve the prescribed calories, and reasons for interruptions of feeds were collected. Primary outcome analyzed was adequacy of nutrition ( $>80 \%$ prescribed dose), and secondary outcomes analyzed were ventilator days and ICU LOS.

Results: A total of $622 \mathrm{MV}$ patients were analyzed. $36.1 \%$ of patients were at nutritional risk (mNUTRIC $\geq 5$ ). $89 \%$ of patients received EN, and the time taken to start EN in these patients was 10 hours (6-20) (median [IQR]). Only $29.6 \%$ of patients achieved nutritional adequacy. Time taken for this was 36 hours (median). On average, patients on MV received 63\% (1025 kcal) and 57\% (41 g) of their prescribed calories and proteins, respectively. The most common reasons for withholding feeds were airway-related procedures (68.2\%) followed by Gl intolerance (15\%). Frequent interruptions of EN, patients on $>1$ vasopressors, and surgical admissions were reasons for nutritional inadequacy. Nutritional adequacy had no impact on clinical outcomes.

Conclusion: Despite following guidelines and feeding protocols, there exists a wide gap between prescribed nutrition and what is actually delivered in MV patients.

Keywords: Critically ill, Enteral nutrition, Mechanical ventilation, Nutritional status.

Indian Journal of Critical Care Medicine (2021): 10.5005/jp-journals-10071-23717
\end{abstract}

\section{INTRODUCTION}

Critically ill patients are under stress which initiates a variety of metabolic responses like muscle wasting and stress hyperglycemia. Nutritional support in these patients helps attenuate these metabolic responses to stress. ${ }^{1}$ Malnutrition in critically ill patients has been associated with poor outcomes, including prolonged mechanical ventilation, increased risk of infection, and higher mortality. ${ }^{2}$ Hypercatabolic state associated with critical illness may further increase the risk of adverse outcomes among intensive care unit (ICU) patients who receive inadequate nutrition. Early enteral nutrition (EN) reduces the metabolic response to stress, decreases bacterial translocation, and maintains gut mucosal integrity.

Heyland et al. $^{3}$ in their study on nutritional adequacy in mechanically ventilated (MV) patients concluded that providing $80 \%$ of prescribed calories results in better clinical outcomes. In practice, achieving such high targets is difficult. Previous studies on nutritional adequacy in MV patients have achieved only $59 \%$ of the prescribed calories. ${ }^{4,5}$ Even though many international studies have looked at this important aspect of nutritional adequacy in critical care management, there is a paucity of data from Indian ICUs especially among the sickest cohort of patients. ${ }^{4,5}$ Additionally, acceptance and practice of nutritional support especially in MV patients is still not universal in our country. Hence, we decided to study the gap between our nutrition prescription and the nutrition

\footnotetext{
1,2Department of Critical Care Medicine, Saveetha Medical College and Hospital, Chennai, Tamil Nadu, India

${ }^{3}$ Department of Anaesthesiology and Critical Care Medicine, Sri Ramachandra Medical Centre, Sri Ramachandra Institute of Higher Education and Research, Chennai, Tamil Nadu, India

${ }^{4}$ Department of Critical Care Medicine, AIG Hospitals, Hyderabad, Telangana, India

Corresponding Author: MS Kalaiselvan, Department of Critical Care Medicine, Saveetha Medical College and Hospital, Chennai, Tamil Nadu, India, Phone: +91 9962334411, e-mail: kalaiselvan.m.s@gmail.com

How to cite this article: Kalaiselvan MS, Arunkumar AS, Renuka MK, Sivakumar RL. Nutritional Adequacy in Mechanically Ventilated Patient: Are We Doing Enough? Indian J Crit Care Med 2021;25(2):166-171.

Source of support: Nil

Conflict of interest: None
}

targets achieved along with the reasons for failure to achieve those targets.

\section{Materials and Methods}

This study was a prospective observational study conducted in a 25-bedded multidisciplinary ICU of a university teaching hospital 
during the period from January 2015 to May 2017. This study was approved by the Institutional Ethics Committee. Patient consent was obtained before data collection. All adult ( $>18$ years) critically ill patients who required mechanical ventilation for more than 48 hours were included in this study. Patients who were readmitted to the ICU during the same hospital stay and transferred out to other ICUs were excluded from this study. All MV patients had orogastric/ nasogastric tube placed during endotracheal intubation or on admission to ICU. The position of orogastric/nasogastric tube was confirmed with chest radiograph, before the initiation of feeds. EN consisted of a standard polymeric isocaloric formula $(1 \mathrm{~m} 1 \simeq$ $1 \mathrm{kcal}$ ) delivered as a continuous infusion over 24 hours. In special situations like fluid restriction, calorie dense formula (1 $\mathrm{m} 1 \simeq 2 \mathrm{kcal})$ was provided. Patients were prescribed EN targeted to achieve $25 \mathrm{kcal} / \mathrm{kg}$ per day (ideal body weight) of energy and $1.2 \mathrm{~g} / \mathrm{kg}$ per day of proteins. All MV patients were started on EN unless contraindicated. Feeds were initiated at an infusion rate of $30 \mathrm{~mL} /$ $\mathrm{hr}$ and increased stepwise every 4 hours to a maximum of $100 \mathrm{~mL}$ $/ \mathrm{hr}$ and subsequently maintained to reach the targeted calories as per the standard existing ICU protocol.

Primary outcome analyzed was nutritional adequacy defined as achievement of $80 \%$ of prescribed energy. ${ }^{3}$ Secondary outcomes analyzed included duration of mechanical ventilation, ICU LOS, and mortality. Data were collected on demography, body mass index (BMI), indication for ICU admission, admission category (medical vs surgical), and admission APACHE II and SOFA scores, and nutritional risk was captured with the modified NUTRIC score (with the exception of IL-6). Nutritional data on type of feed initiated, amount of calories prescribed/achieved, time taken to initiate feeds, reasons for not starting/delay in starting feeds, time taken to achieve the prescribed calories, and reasons for interruptions of feeds were collected. The risk factors for not achieving $>80 \%$ of prescribed calories were analyzed. Secondary outcome data were collected on ventilator days, average ICU length of stay (ALOS), and mortality.

The energy adequacy and the protein adequacy were calculated as follows:

$\begin{aligned} & \text { Energy } \\ & \text { adequacy }(\%)=\frac{\text { [Sum of percentage of calories received/ }}{\text { prescribed each day }]}\end{aligned}$
$\begin{aligned} & \text { Protein } \\ & \text { adequacy }(\%)=\frac{\text { Total number of evaluable nutrition days. }}{\text { [Sum of percentage of protein received/ }} \\ & \text { prescribed each day }]\end{aligned}$
Total number of evaluable nutrition days.

This was then followed up daily till extubation.

Data were analyzed using IBM. SPSS Statistics Software 23.0 version. Continuous variables were described as mean and standard deviation, and categorical variables as percentage. The normality of the data was verified with Kolmogorov-Smirnov test. The difference between the bivariate samples in independent groups was analyzed using the unpaired sample t-test for normal data and Mann-Whitney U-test for skewed data. Categorical data were analyzed using chi-square and Fisher's exact tests. In all the above statistical tools, the probability value of 0.05 was considered as significant level. Sample size was calculated based on the study by Weijs et al. ${ }^{6}$ Considering the expected $50 \%$ reduction in adverse ICU outcomes in MV patients with nutritional adequacy and a precision level of $4 \%$ with $5 \%$ of alpha error, the calculated sample size was 600 , and by allowing $5 \%$ of data loss, 630 samples were considered for the study.

\section{Results}

$1032 \mathrm{MV}$ patients were admitted during the study period, of whom 260 patients on MV for $<48$ hours did not form part of the study. 51 patients who were readmitted to ICU during the same hospital stay and 99 patients who were transferred to other ICUs were excluded from the study. Data of 622 patients were analyzed. More than twothirds of the patients were male. The mean age of patients was 55.8 $( \pm 17.8)( \pm$ SD) years. Admission APACHE II and SOFA scores were 22.1 $( \pm 7.1)( \pm S D)$ and $7.7( \pm 3.0)( \pm S D)$, respectively. The mean NUTRIC score of patients was $3.9( \pm 1.9)$. $225(36.1 \%)$ patients were at nutritional risk (NUTRIC score $\geq 5$ ) (Table 1). $66 \%$ of patients were at medical admissions. The most common coexisting illnesses on admission were diabetes mellitus (33\%) followed by hypertension (32.7\%) and chronic kidney disease (11.9\%). Almost one-quarter of MV patients required at least one vasopressor (25.8\%), and $7.5 \%$ of patients required more than one vasopressor for maintaining MAP $>65 \mathrm{~mm} \mathrm{Hg}$. The mean lactate level on admission was $2.52( \pm 2.2)( \pm S D) \mathrm{mmol} / \mathrm{L}$.

The majority of patients received EN (89.1\%), followed by parenteral nutrition (PN) (1.2\%). $0.8 \%$ of patients received both $\mathrm{EN}$ and $\mathrm{PN}$, and $8.2 \%$ of patients did not receive any nutritional support (Table 2) (Fig. 1). Among the patients who did not receive any nutritional support $(n=51)$, most were postoperative patients $(n=27)$, followed by those awaiting procedures $(n=9)$ and patients

Table 1: Patient characteristics

\begin{tabular}{|c|c|}
\hline & $n=622$ \\
\hline Age (mean $\pm S D)$ years & $55.8 \pm 17.8$ \\
\hline Male $n(\%)$ & $414(66.5)$ \\
\hline Female $n(\%)$ & $208(33.5)$ \\
\hline $\mathrm{BMI}^{\mathrm{a}}($ mean $\pm \mathrm{SD})\left(\mathrm{kg} / \mathrm{m}^{2}\right)$ & $24.4 \pm 4.0$ \\
\hline mNUTRIC ${ }^{b}$ score (mean \pm SD) & $3.9 \pm 1.9$ \\
\hline Low mNUTRIC score $(\leq 4) n(\%)$ & $397(63.8)$ \\
\hline High mNUTRIC score $(\geq 5) n(\%)$ & $225(36.1)$ \\
\hline $\mathrm{APACHE}^{\mathrm{C}} \mathrm{II}($ mean $\pm \mathrm{SD})$ & $22.12 \pm 7.1$ \\
\hline $\operatorname{SOFA}^{\mathrm{d}}(\operatorname{mean} \pm \mathrm{SD})$ & $7.7 \pm 3.0$ \\
\hline Serum Albumin (mean $\pm \mathrm{SD}$ ) g/dL & $3.31 \pm 0.71$ \\
\hline Serum Lactate (mean $\pm \mathrm{SD}$ ) $\mathrm{mmol} / \mathrm{L}$ & $2.52 \pm 2.24$ \\
\hline Requirement of one vasopressor $n(\%)$ & $161(25.8)$ \\
\hline Requirement of $>1$ vasopressor $n(\%)$ & $47(7.5)$ \\
\hline Admission category & $n(\%)$ \\
\hline Medicine & $411(66.1)$ \\
\hline Surgery & $211(33.9)$ \\
\hline Comorbid diseases & $n(\%)$ \\
\hline Diabetes mellitus & $206(33.1)$ \\
\hline Hypertension & $204(32.7)$ \\
\hline Chronic kidney disease & $74(11.9)$ \\
\hline Coronary artery disease & $46(7.4)$ \\
\hline Chronic obstructive airway disease & $40(6.4)$ \\
\hline Chronic liver disease & $30(4.8)$ \\
\hline \multicolumn{2}{|l|}{ Outcome data } \\
\hline Average ICU length of stay (mean \pm SD) days & $8.3 \pm 5.3$ \\
\hline Ventilator days (mean \pm SD) & $6.4 \pm 4.2$ \\
\hline Mortality $n(\%)$ & $204(32.8 \%)$ \\
\hline
\end{tabular}


Table 2: Nutritional data in MV patients $(n=622)$

\begin{tabular}{|c|c|}
\hline Nutrition therapy initiated & $n(\%)$ \\
\hline Enteral nutrition (EN) & $554(89.1)$ \\
\hline Parenteral nutrition (PN) & $12(1.9)$ \\
\hline $\mathrm{EN}+\mathrm{PN}$ & $5(0.8)$ \\
\hline No feeding & $51(8.2)$ \\
\hline Nutrition prescription & Mean \pm SD \\
\hline Mean energy kcal/day & $1623 \pm 263$ \\
\hline Mean protein g/day & $72 \pm 10.5$ \\
\hline \multicolumn{2}{|l|}{ Nutrition received } \\
\hline Mean energy kcal/day (\%) & $1025 \pm 124(63.1)$ \\
\hline Mean protein g/day (\%) & $41.0 \pm 7.2(57)$ \\
\hline $\begin{array}{l}\text { Time taken to initiate feed following ICU } \\
\text { admission. Median (IQR) hours. }\end{array}$ & $10(6-20)$ \\
\hline $\begin{array}{l}\text { No of patients achieved nutritional adequacy } \\
\text { [>80\%prescribed calorie] } n(\%)\end{array}$ & $184(29.6)$ \\
\hline $\begin{array}{l}\text { Patients with high mNUTRIC score }(\geq 5) \text {, who } \\
\text { achieved }>80 \% \text { nutritional adequacy } n(\%) \text {. }\end{array}$ & $68 / 225(30.2 \%)$ \\
\hline $\begin{array}{l}\text { Time taken to achieve prescribed calories } \\
\text { (median) hours. }\end{array}$ & 36 \\
\hline Energy achieved in day $1 \mathrm{kcal} /$ day (\%) & $647 \pm 527(39.8)$ \\
\hline Protein achieved in day $1 \mathrm{~g} /$ day (\%) & $25.4 \pm 21.9(35.2)$ \\
\hline Blood glucose (mg/dL) day 1 & $151.9 \pm 56.1$ \\
\hline Insulin administered (units) day 1 & $11 \pm 22.54$ \\
\hline Energy achieved in day $2 \mathrm{kcal} /$ day (\%) & $1252.4 \pm 756.5(77.3)$ \\
\hline Protein achieved in day 2 g/day (\%) & $50.74 \pm 35.86(70.4)$ \\
\hline Blood glucose $(\mathrm{mg} / \mathrm{dL})$ day 2 & $155.87 \pm 52.8$ \\
\hline Insulin administered (units) day 2 & $14.1 \pm 27.12$ \\
\hline Energy achieved in day $3 \mathrm{kcal} /$ day (\%) & $1233.48 \pm 787.4(76)$ \\
\hline Protein achieved in day 3 g/day (\%) & $49.48 \pm 19.52(68.7)$ \\
\hline Blood glucose $(\mathrm{mg} / \mathrm{dL})$ day 3 & $158 \pm 60.3$ \\
\hline Insulin administered (units) day 3 & $15.1 \pm 29.4$ \\
\hline Nutrition evaluable days (mean \pm SD) & $7.0 \pm 3.2$ \\
\hline
\end{tabular}

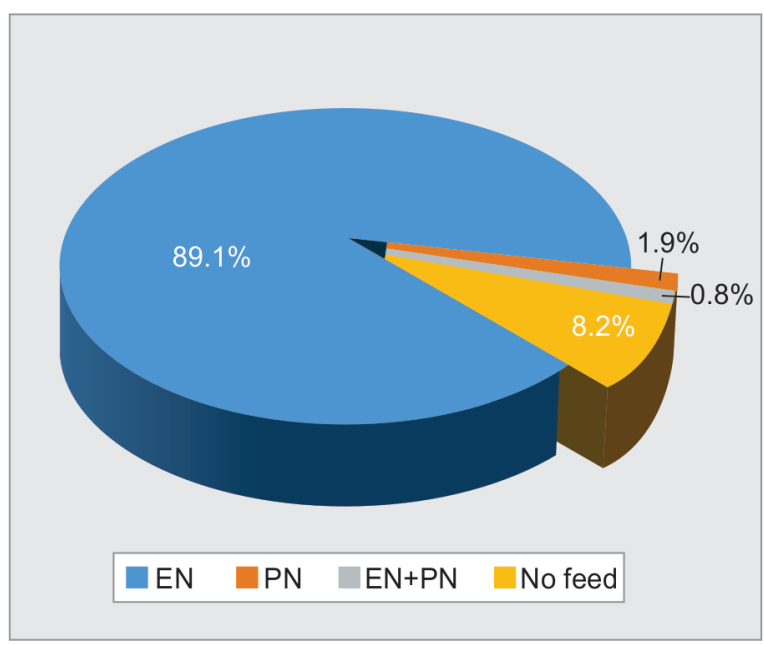

Fig. 1: Nutritional practice in MV patients

Table 3: Reasons for not starting feeds/delay in starting feeds

\begin{tabular}{lc}
\hline Reasons for not starting feeds & $n=51$ \\
Postoperative case & 27 \\
Awaiting procedure & 9 \\
Shock requiring high dose of vasopressors & 6 \\
Upper Gl bleed & 6 \\
Poison/toxin ingestion & 3 \\
Reasons for delay in starting feeds (>48 hours) & $n=87$ \\
Shock requiring high dose of vasopressors & 30 \\
Postoperative patients & 19 \\
Poison/toxin ingestion & 7 \\
Upper Gl bleed & 4 \\
\hline
\end{tabular}
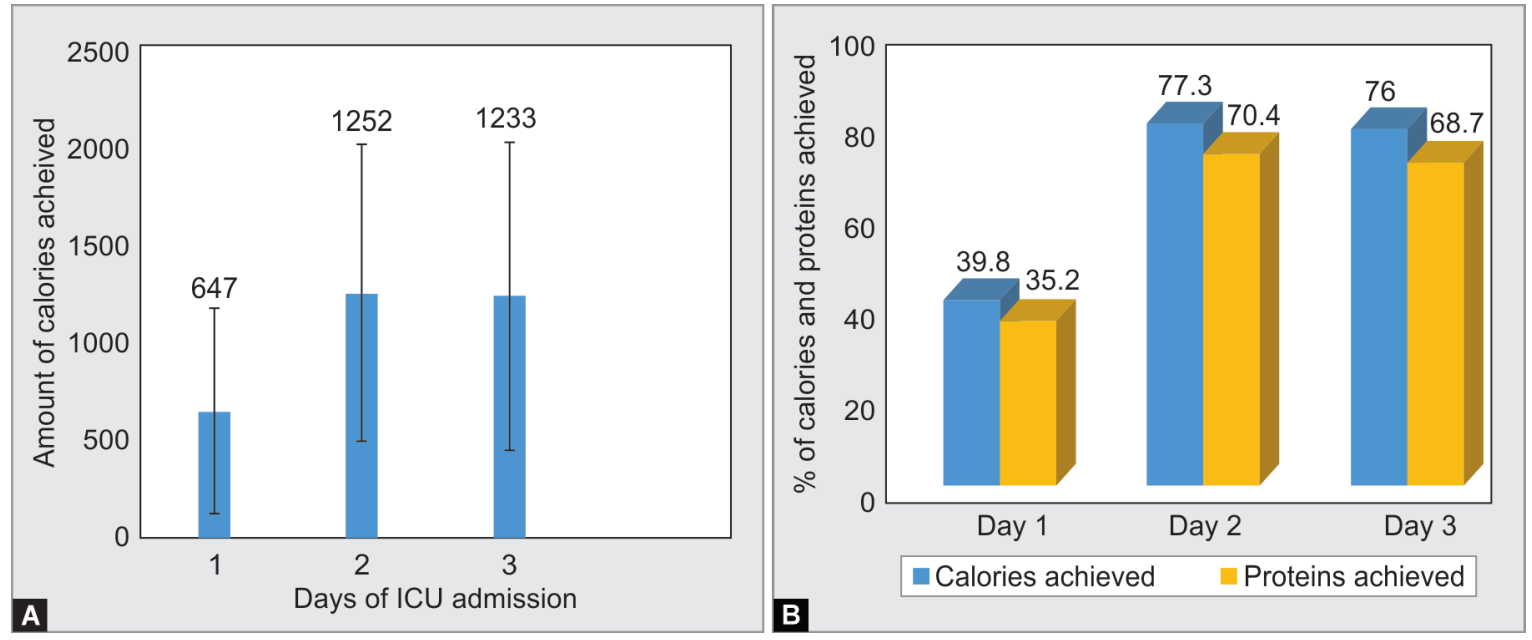

Fig. 2A and B: (A) Amount of calories received over days; (B) Energy and proteins achieved over days

on multiple vasopressors $(n=6)$ (Table 3). Mean calories and proteins prescribed to these patients were $1623( \pm 263) \mathrm{kcal} /$ day and $72( \pm 10.5) \mathrm{g} /$ day, respectively. 184 (29.6\%) patients achieved $80 \%$ of their prescribed calories. This was achieved in 36 hours (median).
Median time taken to start EN in these patients was 10 hours $(6-20$ IQR) with a range of $0-130$ hours. On average, patients received $39.8 \%$ of their prescribed calories and $35.2 \%$ of prescribed proteins on Day 1 of ICU admission (Fig. 2). Patients on mechanical ventilation 


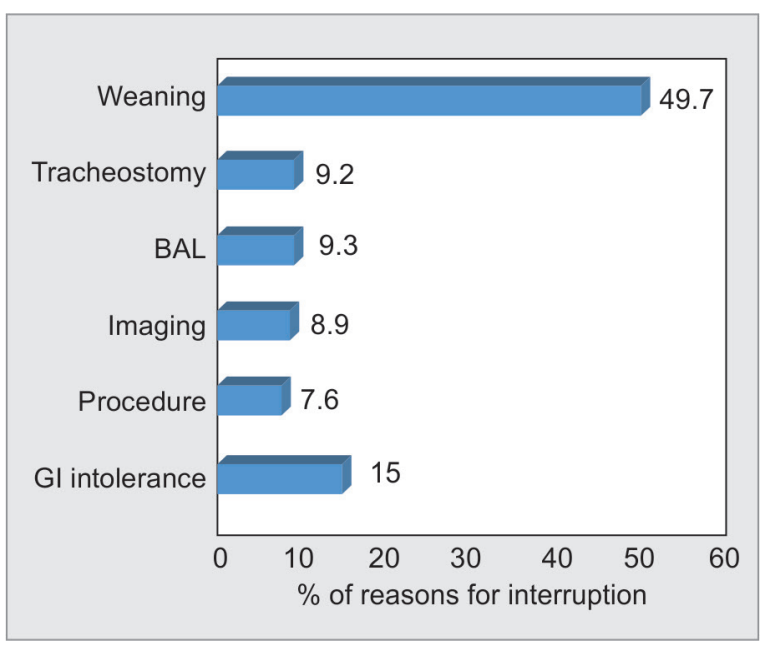

Fig. 3: Reasons for interrupting feeds

Table 4: Reasons for interrupting/withholding feeds

\begin{tabular}{lc}
\hline No. of episodes of interruptions of EN & $n=923$ \\
Weaning \& Extubation $n(\%)$ & $459(49.7)$ \\
Tracheostomy $n(\%)$ & $85(9.2)$ \\
Bronchoalveolar lavage $n(\%)$ & $86(9.3)$ \\
Imaging procedures (CT/MRI) $n(\%)$ & $83(8.9)$ \\
Posted for procedure $n(\%)$ & $71(7.6)$ \\
Gl intolerance $n(\%)$ & $139(15.0)$ \\
Time taken to restart feeds following interruption of & $10(8-12)$ \\
EN [median (IQR)] hours & \\
\hline
\end{tabular}

received $63 \%$ (1025 kcal) and 57\% (41 g) of their prescribed calories and proteins. Of the 225 patients with highly modified NUTRIC score $(\geq 5)$, only $30.2 \%$ achieved a nutritional target of $>80 \%$. A delay in starting nutritional support (>48 hours) was seen in 87 (13.9\%) patients. The delay was mostly commonly observed in patients requiring $>1$ vasopressor support $(n=30)$ and postsurgical patients $(n=19)$ (Table 3).

A total of 923 episodes of interruption of feeding were observed in 554 patients who were enterally fed. Airway-related procedures were the most common reason for withholding feeds, which included weaning and extubation (49.7\%) followed by tracheostomy (9.2\%) and bronchoalveolar lavage (9.3\%) (Fig. 3). Gastrointestinal intolerance (vomiting/regurgitation, diarrhea, and abdominal distention) was observed in $15 \%$ of patients (Table 4). Median time taken to restart feeding after the interruption of feed was 10 hours [median IQR (8-12)]. Patients required mechanical ventilation for $6.4( \pm 4.2)( \pm S D)$ days. ALOS was $8.3( \pm 5.3)( \pm$ SD) days. Mortality in this study was $32.8 \%$.

Multivariate regression analysis identified surgical admissions, patients on $>1$ vasopressors support, delay in starting feeds ( $>48$ hours of $\mathrm{MV}$ ), and frequent interruptions during EN as risk factors for not achieving nutritional adequacy $(p<0.05)$ (Table 5). Ventilator days, ICU LOS, and mortality were similar in those who achieved prescribed nutritional targets compared to those who did not achieve nutritional targets.

\section{Discussion}

This study highlights the gap in nutrition prescription and target achievement in critically ill MV patients in ICU, and also tries to
Table 5: Comparison of patients who achieved nutritional adequacy versus inadequacy

\begin{tabular}{|c|c|c|c|}
\hline & $\begin{array}{l}\text { Nutritional adequacy } \\
(>80 \% \text { prescribed } \\
\text { calories) }(n=184)\end{array}$ & $\begin{array}{l}\text { Nutritional } \\
\text { inadequacy } \\
(n=438)\end{array}$ & Significance \\
\hline $\begin{array}{l}\text { Age }(\text { mean } \pm S D) \\
\text { years }\end{array}$ & $56.59 \pm 18.9$ & $55.83 \pm 17.4$ & 0.42 \\
\hline $\begin{array}{l}\mathrm{BMI}^{\mathrm{a}}(\text { mean } \pm \mathrm{SD}) \\
\left(\mathrm{kg} / \mathrm{m}^{2}\right)\end{array}$ & $23.11 \pm 4.36$ & $24.95 \pm 3.75$ & 0.32 \\
\hline $\begin{array}{l}\text { mNUTRIC }{ }^{b} \text { score } \\
(\text { mean } \pm S D)\end{array}$ & $3.8 \pm 2.1$ & $4.0 \pm 1.7$ & 0.45 \\
\hline $\begin{array}{l}\mathrm{APACHE}^{\complement} \| \\
(\text { mean } \pm \mathrm{SD})\end{array}$ & $21.8 \pm 7.1$ & $22.2 \pm 7.2$ & 0.12 \\
\hline $\operatorname{SOFA}^{\mathrm{d}}($ mean $\pm \mathrm{SD})$ & $7.43 \pm 3.0$ & $7.84 \pm 3.0$ & 0.13 \\
\hline $\begin{array}{l}\text { Serum lactate } \\
\text { (mean } \pm \mathrm{SD}) \\
\mathrm{mmol} / \mathrm{L}\end{array}$ & $2.0 \pm 2.24$ & $2.5 \pm 2.2$ & 0.31 \\
\hline $\begin{array}{l}\text { Serum albumin } \\
(\text { mean } \pm S D) \mathrm{mg} / \mathrm{dL}\end{array}$ & $3.38 \pm 0.7$ & $3.28 \pm 0.7$ & 0.43 \\
\hline $\begin{array}{l}\text { Requirement of } \\
\text { one vasopressors } \\
n(\%)\end{array}$ & $57(31)$ & $148(33.8)$ & 0.46 \\
\hline $\begin{array}{l}\text { Requirement of } \\
>1 \text { vasopressors } \\
n(\%)\end{array}$ & $9(4.9)$ & $36(8.2)$ & 0.03 \\
\hline $\begin{array}{l}\text { Admission } \\
\text { category }\end{array}$ & & & $<0.001$ \\
\hline Medicine & $150(81.5)$ & $261(59.6)$ & \\
\hline Surgery & $34(18.4)$ & $177(40.4)$ & \\
\hline $\begin{array}{l}\text { Time taken to } \\
\text { initiate feeds } \\
\text { (median } \\
\text { [IQR25-75]) hours }\end{array}$ & $8[6-13]$ & $12[6-24]$ & \\
\hline $\begin{array}{l}\text { No of episodes of } \\
\text { EN interruption }(n)\end{array}$ & 202 & 721 & $<0.001$ \\
\hline \multicolumn{4}{|l|}{ Outcome data } \\
\hline $\begin{array}{l}\text { Average ICU } \\
\text { length of stay } \\
\text { (mean } \pm S D \text { ) days }\end{array}$ & $8.32 \pm 5.38$ & $7.53 \pm 4.39$ & 0.10 \\
\hline $\begin{array}{l}\text { Ventilator days } \\
\text { (mean } \pm \text { SD) }\end{array}$ & $6.46 \pm 4.27$ & $5.9 \pm 3.9$ & 0.23 \\
\hline Mortality $n(\%)$ & $64(34.8)$ & $142(32.4)$ & 0.62 \\
\hline
\end{tabular}

${ }^{a} B M I$, body mass index; ${ }^{b}$ NUTRIC, nutrition risk in the critically ill; ' $A$ APACHE II, acute physiology and chronic health evaluation II; ${ }^{d}$ SOFA, sepsis-related organ failure assessment score

unearth the reasons for the same in the Indian scenario. In spite of a protocolled nutrition prescription, only $29.6 \%$ of patients achieved nutritional adequacy. In this study, MV patients received only $63 \%$ of their prescribed calories and $57 \%$ of their prescribed proteins during their ICU stay. Nutritional adequacy in our study was similar to those described by Cahill et al. ${ }^{4}$ and Ridley et al., ${ }^{7}$ where they observed nutritional adequacy of 59 and $56 \%$ of prescribed calories, respectively, in MV patients.

A total of $36 \%$ of MV patients were at nutritional risk (mNUTRIC score $\geq 5$ ). Only $30.2 \%$ of these patients were able to achieve nutritional adequacy ( $>80 \%$ prescribed) in our study. This was higher than those described by Heyland et al., ${ }^{3}$ where only $20 \%$ of MV patients with high mNUTRIC score achieved 
nutritional adequacy. Achieving nutritional adequacy in critically ill patients is challenging due to various factors like high incidence of GI intolerance to enteral feeds, requirement of multiple vasopressor support, etc. ${ }^{8}$ EN was initiated comparatively earlier in our study [10 hours (median)]. Described lead time to the initiation of EN in MV patients is quite varied ranging from 8.2 to 149 hours. $4,7,9$

Studies have identified the interruption of EN as the primary reason for nutritional inadequacy in ICU patients. ${ }^{9-12}$ We too found that interruptions to feeds were significantly associated with inadequacy of nutrition. Ramakrishnan et al. ${ }^{13}$ similarly reported $55.7 \%$ interruptions of EN for procedures inside ICU. Airwayrelated procedures (weaning, tracheostomy, and $\mathrm{BAL}$ ) were the main reasons for withholding EN (67\%). Timing of withholding enteral feeding for scheduled procedures varies significantly with the type of specialty managing the critical care units. Schneider et al. ${ }^{14}$ compared the practice of withholding EN before scheduled procedures between different training programs and found longer withholding time with anesthesia ( 6 hours) compared to medical (1.5 hours) managing critical care programs before extubation. Other risk factors for nutritional adequacy include the requirement of $>1$ vasopressor support and surgical admissions. Many strategies have been suggested to increase the nutritional adequacy in critically ill patients, like providing calorie dense feed (TARGET trial) and providing earlier parenteral nutrition (EPaNIC). ${ }^{15-17}$ Chapman et al. $^{16}$ in the TARGET trial compared patients who received calorie dense feed (1863 kcal) vs those who received isocaloric feed (1262 kcal) and found no difference in patient's outcomes. Casaer et al. $^{17}$ from the EPaNIC trial compared early vs initiation of PN and showed that the late initiation of PN compared to the early initiation is associated with faster recovery and fewer complications in critically ill patients.

Our study did not find any association between nutritional adequacy and duration of mechanical ventilation or length of stay in ICU. Evidence linking adequacy of nutrition during ICU stay to clinical outcomes is varied. While certain studies found no benefit or harm with nutritional adequacy, ${ }_{15-18}$ others like Rahman et al. ${ }^{19}$ reported that there is a strong positive association between nutritional adequacy and 28-day mortality in patients with high NUTRIC scores. Compher et al. ${ }^{20}$ found that greater nutritional intake in MV patients with high NUTRIC scores was associated with lower mortality and faster time to discharge alive.

Achieving nutritional adequacy in critically ill patients, especially in those at nutritional risk, is at best a very challenging task. Clinicians and individual critical care units need to devise their own strategies to ease this process keeping in mind their unique circumstances. Some of these strategies include defining lower fasting targets before procedures, paying attention to reinitiating feeds at the earliest after an interruption, and possible use of hybrid methods encompassing both enteral and parenteral modes especially in those at high nutritional risk.

Even though our study did not find any impact of nutrition support on clinical outcomes, it still is a very large prospectively compiled sample of critically ill patients on mechanical ventilation for more than 48 hours from India. Another strength of our study is that we followed up patients till they were transferred out of ICU, hence giving a wholesome picture of nutritional support throughout ICU stay.

There were various limitations to our study. We did not calculate the calories provided by propofol infusion, which is a common practice in our ICU. We used weight-based prescription of calories and proteins instead of indirect calorimetry, which would be the ideal way to calculate the resting energy expenditure in MV patients (ASPEN and ESPEN guidelines). ${ }^{21,22}$ We also do not have post-ICU follow-up of these patients, hence missing out on the important long-term clinical outcomes.

\section{Conclusion}

Despite following recommendations and feeding protocols, there exists a wide gap between prescribed nutrition and actual calories and proteins received by critically ill, MV patients in ICUs. We need to devise further strategies to improve this. We also need to have a larger study in the Indian scenario to understand the impact of nutritional adequacy on clinical outcomes.

\section{Acknowledgment}

We would like to thank Miss Deepa for helping us in collecting the data.

\section{ORCID}

Kalaiselvan MS ๑ https://orcid.org/0000-0001-8098-5345

\section{References}

1. Puthucheary ZA, Rawal J, McPhail M, Connolly B, Ratnayake G, Chan $P$, et al. Acute skeletal muscle wasting in critical illness. JAMA 2013;310(15):1591-1600. DOI: 10.1001/jama.2013.278481.

2. Correia MI, Waitzberg DL. The impact of malnutrition on morbidity, mortality, length of hospital stays and costs evaluated through a multivariate model analysis. Clin Nutr 2003;22(3):235-239.DOI: 10.1016/ s0261-5614(02)00215-7.

3. Heyland DK, Cahill N, Day A. Optimal amount of calories for critically ill patients: depends on how you slice the cake! Crit Care Med 2011;39(12): 2619-2626. DOI: 10.1097/CCM.0b013e318226641d.

4. Cahill NE, Dhaliwal R, Day AG, Jiang X, Heyland DK. Nutrition therapy in the critical care setting: what is "best achievable" practice? An international multicenter observational study. Crit Care Med 2010;38(2):395-401. DOI: 10.1097/CCM.0b013e3181c0263d.

5. Alberda C, Gramlich L, Jones N, Jeejeebhoy K, Day AG, Dhaliwal R, et al. The relationship between nutritional intake and clinical outcomes in critically ill patients: results of an international multicenter observational study. Intensive Care Med 2009;35(10):1728-1737. DOI: 10.1007/s00134-009-1567-4.

6. Weijs PJ, Stapel SN, de Groot SD, Driessen RH, de Jong E, Girbes $A R$, et al. Optimal protein and energy nutrition decreases mortality in mechanically ventilated, critically ill patients: a prospective observational cohort study. JPEN J Parenter Enteral Nutr 2012;36(1):60-68. DOI: 10.1177/0148607111415109.

7. Ridley EJ, Peake SL, Jarvis M, Deane AM, Lange K, Davies AR, et al. Nutrition therapy in Australia and New Zealand intensive care units: an international comparison study. JPEN J Parenter Enteral Nutr 2018;42(8):1349-1357. DOI: 10.1002/jpen.1163.

8. Ritter CG, Medeiros IMS, Pádua CS, Gimenes FRE, Prado PRD. Risk factors for protein-caloric inadequacy in patients in an intensive care unit. Rev Bras Ter Intensiva 2019;31(4):504-510. DOI: 10.5935/0103507X.20190067.

9. Yip KF, Rai V, Wong KK. Evaluation of delivery of enteral nutrition in mechanically ventilated Malaysian ICU patients. BMC Anesthesiol 2014;14:127. DOI: 10.1186/1471-2253-14-127.

10. Heyland DK, Dhaliwal R, Wang M, Day AG. The prevalence of iatrogenic underfeeding in the nutritionally 'at-risk' critically ill patient: results of an international, multicenter, prospective study. Clin Nutr 2015;34(4):659-666. DOI: 10.1016/j.clnu.2014.07.008. 
11. Passier RH, Davies AR, Ridley E, McClure J, Murphy D, Scheinkestel $C D$. Periprocedural cessation of nutrition in the intensive care unit: opportunities for improvement. Intensive Care Med 2013;39(7):12211226. DOI: 10.1007/s00134-013-2934-8.

12. Uozumi $M$, Sanui $M$, Komuro $T$, lizuka $Y$, Kamio $T$, Koyama $H_{\text {, }}$ et al. Interruption of enteral nutrition in the intensive care unit: a single center survey. ICMx 2015;3:A289. DOI: 10.1186/2197-425X-3S1-A289.

13. Ramakrishnan N, Daphnee DK, Ranganathan L, Bhuvaneshwari S. Critical care $24 \times 7$ : but, why is critical nutrition interrupted? Indian J Crit Care Med 2014;18(3):144-148. DOI: 10.4103/0972-5229.128704.

14. Schneider JA, Lee YJ, Grubb WR, Denny J, Hunter C. Institutional practices of withholding enteral feeding from intubated patients. Crit Care Med 2009;37(7):2299-2302. DOI: 10.1097/ CCM.0b013e3181a007eb.

15. Allingstrup MJ, Kondrup J, Wiis J, Claudius C, Pedersen UG, HeinRasmussen R, et al. Early goal-directed nutrition versus standard of care in adult intensive care patients: the single-centre, randomised, outcome assessor-blinded EAT-ICU trial. Intensive Care Med 2017;43(11):1637-1647. DOI: 10.1007/s00134-017-4880-3.

16. Chapman M, Peake SL. Energy-dense versus routine enteral nutrition in the critically III. N Engl J Med 2018;379:1823-1834. DOI: 10.1056/ NEJMoa1811687.

17. Casaer MP, Mesotten D, Hermans G, Wouters PJ, Schetz M, Meyfroidt $G$, et al. Early versus late parenteral nutrition in critically ill adults. N Engl J Med 2011;365(6):506-517. DOI: 10.1056/ NEJMoa1102662.

18. Arabi YM, Aldawood AS, Haddad SH, Al-Dorzi HM, Tamim HM, Jones $\mathrm{G}$, et al. Permissive Underfeeding or Standard Enteral Feeding in Critically III Adults. N Engl J Med 2015;372(25):2398-2408. DOI: 10.1056/NEJMoa1502826.

19. Rahman A, Hasan RM, Agarwala R, Martin C, Day AG, Heyland DK. Identifying critically-ill patients who will benefit most from nutritional therapy: further validation of the "modified NUTRIC" nutritional risk assessment tool. Clin Nutr 2016;35(1):158-162. DOI: 10.1016/j. clnu.2015.01.015.

20. Compher C, Chittams J, Sammarco T, Nicolo M, Heyland DK. Greater protein and energy intake may be associated with improved mortality in higher risk critically ill patients: a multicenter, multinational observational study. Crit Care Med 2017;45(2):156-163. DOI: 10.1097/ CCM.0000000000002083.

21. Taylor BE, McClave SA, Martindale RG, Warren MM, Johnson DR, Braunschweig $C$, et al. Guidelines for the provision and assessment of nutrition support therapy in the adult critically ill patient: Society of Critical Care Medicine (SCCM) and American Society for Parenteral and Enteral Nutrition (A.S.P.E.N.). Crit Care Med 2016;44(2):390-438. DOI: $10.1097 /$ CCM.0000000000001525.

22. Singer P, Blaser AR, Berger MM, Alhazzani W, Calder PC, Casaer MP, et al. ESPEN guideline on clinical nutrition in the intensive care unit. Clin Nutr 2019;38(1):48-79. DOI: 10.1016/j.clnu.2018.08.037. 